\title{
Differences between the characteristics of normal tension glaucoma and high tension glaucoma
}

\begin{abstract}
Normal tension glaucoma is a type of primary open angle glaucoma in which the intraocular pressure is in the normal range. Although both normal tension glaucoma and high-tension glaucoma resemble clinically each other, there are some differences between both of them. In this editorial, I aim to summarize the differences between the characteristics of these glaucoma types. If these are well-known, the diagnosis and management of normal tension glaucoma will be easier.
\end{abstract}

Keywords: normal tension glaucoma, normal pressure glaucoma, normotensive glaucoma, high-pressure glaucoma, high tension glaucoma, differences, characteristics
Volume 7 Issue 7 - 2017

Burak Turgut,' Fatoș Altun Turgut ${ }^{2}$

'Department of Ophthalmology, Yuksek Ihtisas University, Turkey

${ }^{2}$ Elazig Training and Research Hospital, Turkey

Correspondence: Burak Turgut, Professor of Ophthalmology Yukseklhtisas University, Faculty of Medicine, Department of Ophthalmology, 06520, Ankara, Turkey,Tel +90 312 280360I, Email burakturgut@yiu.edu.tr

Received: November 22, 2017 | Published: December II, 2017
Abbreviations: NTG, normal tension glaucoma; NPG, normal pressure glaucoma; POAG, primary open angle glaucoma; HPG, high pressure glaucoma; HTG, high tension glaucoma; RNFL, retinal nerve fiber layer; OD, optic disc; RGCs, retinal ganglion Cells; IOP, intra-ocular pressure; GON, glaucomatous optic neuropathy; CNTGS, collaborative normal tension glaucoma study; ODH, optic disc hemorrhage; CCT, central cornea thickness; CSFP, cerebro-spinal fluid pressure; ONPP, optic nerve perfusion pressure; PVD, peripheral vascular dysregulation; OBF, ocular blood flow; OSAS, obstructive sleep apnea syndrome

\section{Editorial}

Glaucoma is defined as a multifactorial and progressive optic neuropathy which usually caused by the effects of elevated intraocular pressure (IOP). Glaucomatous optic neuropathy (GON) is characterized by the excavation of the optic nerve head $(\mathrm{ONH})$, thinning of the retinal nerve fiber layer (RNFL) and the axons of by retinal ganglion cells (RGCs) and eventually the specific loss of visual field (VF). ${ }^{1}$ Primary open-angle glaucoma (POAG) is the most common type of chronic progressive GON with the absence of the association of any ocular disease. POAG includes two types as "'high pressure glaucoma (HPG)/high-tension glaucoma (HTG)" and normal-pressure glaucoma (NPG)/normal tension glaucoma (NTG). ${ }^{1-}$ 5 There are significant overlapping characteristics between both glaucoma types. However, they may be separated by some marked differences in the aspects of risk factors, pathogenesis, OD findings, RNFL thickness and VF defects. ${ }^{6-47}$ Comparison of the characteristics of both glaucoma types has been given in Table 1 .

Table 1 The comparison of the characteristics of NTG and $\mathrm{HTG}^{1,2,4,8,9,11,12,15-20,22-47}$

\begin{tabular}{|c|c|c|}
\hline Characteristics & NTG & HTG \\
\hline IOP & Normal with wide diurnal fluctuations, nocturnal spikes & High with normal range diurnal fluctuations \\
\hline Sexual Predisposition & Female & N/A \\
\hline Possible Specific Risk Factor & $\begin{array}{l}\text { ODH, ischemic/occlusive vascular disease (Migraine, } \\
\text { Raynaud, diabetes, cardiac arrhythmia, stroke) addition to } \\
\text { elevated IOP }\end{array}$ & $\begin{array}{l}\text { High IOP (primary continuous causative risk factor), } \\
\text { Genetic mutation, advanced age, black race, older age, } \\
\text { systemical vascular diseases }\end{array}$ \\
\hline Age & Older average 10 years than HPG & Usually over 50 years old \\
\hline OD Sign & $\begin{array}{l}\text { Narrow NRR, a larger OD surface area, thinner inferior/ } \\
\text { inferotemporal NRR, deep, focal NRR thinning/notching, OD } \\
\text { pit }\end{array}$ & Diffuse NRR thinning, classical GON signs \\
\hline GON Pathogenesis & $\begin{array}{l}\text { Neuro-degeneration, IOP-independent mechanisms (LC } \\
\text { weakness or abnormalities, abnormal easily triggered } \\
\text { apoptosis, low ONBP, low CSFP, local PVD, enhanced } \\
\text { sensitivity to physiologic IOP, hypotension, hematologic } \\
\text { abnormalities) }\end{array}$ & $\begin{array}{l}\text { Neurodegenerative and IOP-dependent mechanisms, } \\
\text { vascular, genetic, and biochemical mechanisms }\end{array}$ \\
\hline PPA & More frequently beta-zone PPA & Beta-zone PPA \\
\hline ONPP & Frequently lower & Maybe lower \\
\hline
\end{tabular}


Table Continued...

\begin{tabular}{lll}
\hline Characteristics & NTG & HTG \\
\hline RNFLT Loss & Earlier, inferotemporal & N/A \\
VF Defects & More focal, central, deeper and closer to fixation & $\begin{array}{l}\text { Deeper, superior nasal step, inferior and superior } \\
\text { paracentral }\end{array}$ \\
SuggestedVF testing protocol I0-2 & $30-2$ \\
CCT & Maybe thinner than average & N/A \\
Genetic Mutation in which & Optineurin & TIGR, Myocilin \\
Systemical BP & Increased diastolic BP and larger dips in BP overnight & N/A \\
ODH & More common & Less common \\
OBF & Strongly impaired & Maybe impaired \\
OSAS & Strongly associated & May be associated \\
Progression & Slower to HPG in the absence of beta-blocker treatment & N/A \\
\hline
\end{tabular}

NTG, normal tension glaucoma; HTG, high tension glaucoma; RNFLT; retinal nerve fiber layer thickness; $V F$, visual field; OD, optic disc; IOP, intra-ocular pressure; GON, glaucomatous optic neuropathy; NRR, neuro-retinal rim; ODH, optic disc hemorrhage; $C C T$, central cornea thickness; PPA, peripapillary atrophy; OBF, ocular blood flow; cerebro-spinal fluid pressure; ONPP, optic nerve perfusion pressure; OSAS, obstructive sleep apnea syndrome; HRT, heidelberg retinal tomography; BP, blood pressure; LC, lamina cribrosa; BP, blood pressure

It has been considered that NTG might occur due to IOP-independent pathogenic factors such as peripheral vascular dysregulation (PVD), hypotension, mechanical factors such as lamina cribrosa (LC) abnormalities and weakness, and enhanced sensitivity of the optic nerve to physiologic IOP. However, CNTGS showed that a $30 \%$ or more reduction of the IOP value in normal range belonging the patient achieved a significant slowdown in the progression of the NTG. ${ }^{6}$ On the other hand, HTG is often an IOP-dependent glaucoma type. IOP plays a great role in the pathogenesis of this glaucoma typ. ${ }^{1}$ In conclusion, as seen in Table 1, compared to those with HTG, the common distinctive findings in the patients with NTG are an IOP value in normal range; female predisposition; optineurin gene mutation; thinner CCT; larger OD size; larger/ deeper OD cupping; thinner LC; frequent NRR notching; earlier and focal RNFL loss; frequent beta zone peripapillary atrophy; frequent OD hemorrhage; frequent pit; deeper, closer to fixation, steeper slopes, more localized and central VF defects; peripheral vascular dysregulation (low nocturnal optic nerve perfusion pressure, cold extremities, impairments in the nail fold capillary, retinal and choroidal blood flow), ocular perfusion abnormalities and vasospastic/ischemic disorders in pathogenesis; associated hematologic abnormalities, obstructive sleep apnea syndrome and blood loss. . $, 3,7-47^{-10}$

\section{Acknowledgments}

None

\section{Conflicts of interest}

The authors declare that there is no conflict of interest regarding the publication of this paper.

\section{Funding}

None.

\section{References}

1. European Glaucoma Society Terminology and Guidelines for Glaucoma, $4^{\text {th }}$ edn, Chapter 2: Classification and terminology. Supported by the EGS Foundation. British J Ophthalmol. 2017;101(5):73-127.

2. Mallick J, Devi L, Malik PK, et al. Update on Normal Tension Glaucoma. J Ophthalmic Vis Res. 2016;11(2):204-208.

3. Tsvi Sheleg. Normal-Tension (Low-Tension) Glaucoma, Glaucoma Basic and Clinical Concepts. In: Rumelt S, editor. In Tech. 2011. p. 602.

4. Pruzan NL, Myers JS. Phenotypic differences in normal vs high tension glaucoma. J Neuroophthalmol. 2015;35(Suppl 1):S4-S7.

5. Mi XS, Yuan TF, So KF. The current research status of normal tension glaucoma. Clin Interv Aging. 2014;9:1563-1571.
6. Collaborative Normal-Tension Glaucoma Study Group. The effectiveness of intraocular pressure reduction in the treatment of normal-tension glaucoma. Am J Ophthalmol. 1998;126(4):498-505.

7. Ng SK, Burdon KP, Fitzgerald JT, et al. Genetic Association at the 9p21 Glaucoma Locus Contributes to Sex Bias in Normal-Tension Glaucoma. Invest Ophthalmol Vis Sci. 2016;57(7):3416-3421.

8. Thonginnetra O, Greenstein VC, Chu D, et al. Normal versus High Tension Glaucoma: a Comparison of Functional and Structural Defects. $J$ Glaucoma. 2010;19(3):151-157.

9. Gutteridge IF. Normal tension glaucoma: diagnostic features and comparisons with primary open angle glaucoma. Clin Exp Optom. 2000;83(3):161-172.

10. Tomita G. The optic nerve head in normal-tension glaucoma. Curr Opin Ophthalmol. 2000;11(2):116-120.

11. Tezel G, Kass MA, Kolker AE, et al. Comparative optic disc analysis in normal pressure glaucoma, primary open-angle glaucoma and ocular hypertension. Ophthalmology. 19996;103(12):2105-2113.

12. Caprioli J, Spaeth GL. Comparison of the optic nerve head in high- and low-tension glaucoma. Arch Ophthalmol. 1985;103(8):1145-1149.

13. Buus DR, Anderson DR. Peripapillary crescents and halos in normal-tension glaucoma and ocular hypertension. Ophthalmology. 1989;96(1):16-19.

14. Yamazaki Y, Hayamizu F, Miyamoto S, et al. Optic disc findings in normal tension glaucoma. Jpn J Ophthalmol. 1997;41(4):260-267. 
15. Shields MB. Normal-tension glaucoma: is it different from primary openangle glaucoma? Curr Opin Ophthalmol. 2008;19(2):85-88.

16. Shetgar AC, Mulimani MB. The central corneal thickness in normal tension glaucoma, primary open angle glaucoma and ocular hypertension. J Clin Diagn Res. 2013;7(6):1063-1067.

17. Ahrlich KG, De Moraes CG, Teng CC, et al. Visual field progression differences between normal-tension and exfoliative high-tension glaucoma. Invest Ophthalmol Vis Sci. 2010;51(3):1458-1463.

18. Araie M. Pattern of visual field defects in normal-tension and hightension glaucoma. Curr Opin Ophthalmol. 1995;6(2):36-45.

19. Park JH, Yoo C, Park J, et al. Visual Field Defects in Young Patients With Open-angle Glaucoma: Comparison Between High-tension and Normaltension Glaucoma. J Glaucoma. 2017;26(6):541-547.

20. Iester M, De Feo F, Douglas GR. Visual Field Loss Morphology in Highand Normal-Tension Glaucoma. J Ophthalmol. 2012;327326.

21. Shin IH, Kang SY, Hong S, et al. Comparison of OCT and HRT Findings among Normal Tension Glaucoma, and High Tension Glaucoma. Korean J Ophthalmol. 2008;22(4):236-241.

22. Eid TE, Spaeth GL, Moster MR, et al. Quantitative Differences between the Optic Nerve Head and Peripapillary Retina in Low-Tension Glaucoma and High-Tension Primary Open-Angle Glaucoma. Am J Ophthalmol. 1997;124(6):805-813.

23. Lee JY, Yoo C, Park JH, et al. Retinal vessel diameter in young patients with open-angle glaucoma: comparison between high-tension and normal-tension glaucoma. Acta Ophthalmol. 2012;90(7):570-571.

24. Mroczkowska S, Benavente-Perez A, Negi A, et al. Primary open-angle glaucoma vs normal-tension glaucoma: the vascular perspective. JAMA Ophthalmol. 2013;131(1):36-43.

25. Harris A, Evans D, Martin B, et al. Effect of nocturnal blood pressure reduction on retrobulbar hemodynamics in glaucoma. Graefes Arch Clin Exp Ophthalmol. 2002;240(10):867-868.

26. Schwenn O, Troost R, Vogel A, et al. Ocular Pulse Amplitude in Patients with Open Angle Glaucoma, Normal Tension Glaucoma, and Ocular Hypertension. Br J Ophthalmol. 2002;86(9):981-984.

27. Kim C, Kim TW. Comparison of risk factors for bilateral and unilatera eye involvement in normal-tension glaucoma. Invest Ophthalmol Vis Sci. 2009;50(3):1215-1220.

28. Meyer JH, Brandi-Dohrn J, Funk J. Twenty four hour blood pressure monitoring in normal tension glaucoma. $\mathrm{Br} J$ Ophthalmol. 1996;80(10):864-847.

29. Flammer J, Orgül S, Costa VP, et al. The impact of ocular blood flow in glaucoma. Prog Retin Eye Res. 2002;21(4):359-393.

30. Okuno T, Sugiyama T, Kojima S, et al. Diurnal Variation in Microcirculation of Ocular Fundus and Visual Field Change in NormalTension Glaucoma. Eye (Lond). 2004;18(7):697-702.
31. Plange N, Remky A, Arend O. Colour Doppler Imaging and Fluorescein Filling Defects of the Optic Disc in Normal Tension Glaucoma. $\mathrm{Br} J$ Ophthalmol. 2003;87(6):731-736.

32. Sung KR, Lee S, Park SB, et al. Twenty-four Hour ocular Perfusion Pressure Fluctuation and Risk of Normal-Tension Glaucoma Progression. Invest Ophthalmol Vis Sci. 2009;50(11):5266-5274.

33. Chang M, Yoo C, Kim SW, et al. Retinal Vessel Diameter, Retinal Nerve Fiber Layer Thickness, and Intraocular Pressure in Korean Patients with Normal-Tension Glaucoma. Am J Ophthalmol. 2011;151(1):100-105.

34. Leske MC. Ocular perfusion pressure and glaucoma: clinical trial and epidemiologic findings. Curr Opin Ophthalmol. 2009;20(2):73-78.

35. Flammer J, Konieczka K, Flammer AJ. The primary vascular dysregulation syndrome: implications for eye diseases. EPMA J. 2013;4(1):14

36. Ramli N, Nurull BS, Hairi NN, et al. Low nocturnal ocular perfusion pressure as a risk factor for normal tension glaucoma. Prev Med. 2013;57(Suppl):S47-S49

37. Berdahl JP, Allingham RR. Intracranial pressure and glaucoma. Curr Opin Ophthalmol. 2010;21(2):106-111.

38. Mansouri K, Liu JH, Weinreb RN, et al. Analysis of continuous 24-hour intraocular pressure patterns in glaucoma. Invest Ophthalmol Vis Sci. 2012;53(13):8050-8056.

39. Phelps CD, Corbett JJ. Migraine, and low-tension glaucoma. A casecontrol study. Invest Ophthalmol Vis Sci. 1985;26(8):1105-1108.

40. Hirooka K, Tenkumo K, Fujiwara A, et al. Evaluation of peripapillary choroidal thickness in patients with normal-tension glaucoma. $B M C$ Ophthalmol. 2012;12:29.

41. Kim SH, Park KH. The relationship between recurrent optic disc hemorrhage and glaucoma progression. Ophthalmology. 2006;113(4):598-602.

42. Ishida K, Yamamoto T, Sugiyama K, et al. Disk hemorrhage is a significantly negative prognostic factor in normal-tension glaucoma. $\mathrm{Am}$ J Ophthalmol. 2000;129(6):707-714.

43. Javitt JC, Spaeth GL, Katz LJ, et al. Acquired pits of the optic nerve: Increased prevalence in patients with low-tension glaucoma. Ophthalmology. 2000;97(8):1038-1043.

44. Ugurlu S, Weitzman M, Nduaguba C, et al. Acquired pit of the optic nerve: A risk factor for progression of glaucoma. Am J Ophthalmol. 1998;125(4):457-464.

45. Cheng HC, Chan CM, Yeh SI, et al. The Hemorheological Mechanisms in Normal Tension Glaucoma. Curr Eye Res. 2011;36(7):647-653.

46. Mojon DS, Hess CW, Goldblum D, et al. Normal-tension glaucoma is associated with sleep apnea syndrome. Ophthalmologica. 2002;216(3):180-184

47. Bilgin G. Normal-tension glaucoma and obstructive sleep apnea syndrome: a prospective study. BMC Ophthalmology. 2014;14:27. 